\title{
Metformin inhibits proliferation and enhances chemosensitivity of intrahepatic cholangiocarcinoma cell lines
}

\author{
SUNBIN LING ${ }^{1,2^{*}}$, TINGTING FENG ${ }^{2,5^{*}}$, QINGHONG KE ${ }^{4}$, NING FAN ${ }^{2,3}$, LEI LI $^{2,3}$, \\ ZHONGXING LI ${ }^{1}$, CHENGYONG DONG ${ }^{1}$, CONG WANG ${ }^{2,3}$, FEI XU ${ }^{3}$, YAN LI $^{2,3}$ and LIMING WANG ${ }^{1}$ \\ ${ }^{1}$ Division of Hepatobiliary and Pancreatic Surgery, Department of Surgery, The Second Affiliated Hospital of \\ Dalian Medical University, Dalian; ${ }^{2}$ Institute of Cancer Stem Cell, Dalian Medical University, Dalian; ${ }^{3}$ College of \\ Basic Medical Sciences, Dalian Medical University, Dalian; ${ }^{4}$ Division of Hepatobiliary and Pancreatic Surgery, \\ Department of Surgery, The First Affiliated Hospital, Zhejiang University, Hangzhou; ${ }^{5}$ Department of \\ Medical Oncology, The Second Affiliated Hospital of Dalian Medical University, Dalian, P.R. China
}

Received February 14, 2014; Accepted April 4, 2014

DOI: 10.3892/or.2014.3151

\begin{abstract}
Metformin is an oral anti-hyperglycemic agent of the biguanide family, which is used first-line for type II diabetes with few side-effects. A recent epidemiological study that included 1,828 potential intrahepatic cholangiocarcinoma (ICC) patients showed that metformin use was significantly associated with a $60 \%$ reduction in ICC risk in diabetic patients, demonstrating the potential value of metformin in ICC management. In the present study, we firstly showed that metformin exhibited a dose- and time-dependent anti-proliferation effect on ICC cell lines, by mechanisms including apoptosis induction and cell cycle arrest. Metformin targeted the AMPK/mTORC1 pathway in ICC cells. Furthermore, metformin sensitized ICC cells to certain chemotherapeutic agents, such as sorafenib, 5-fluorouracil and $\mathrm{As}_{2} \mathrm{O}_{3}$ by targeting the AMPK/mTOR/ HIF-1 $\alpha /$ MRP1 pathway and ERK. As it is an inexpensive and widely used antidiabetic drug without severe adverse effects, metformin may be a prospective chemotherapeutic agent or a chemosensitizer in future ICC treatment.
\end{abstract}

\section{Introduction}

Metformin, a first-line oral anti-type II diabetes agent used worldwide, displays an antitumorigenesis effect, according

Correspondence to: Dr Liming Wang, Department of Surgery, Division of Hepatobiliary and Pancreatic Surgery, The Second Affiliated Hospital of Dalian Medical University, 467 Zhongshan Road, Dalian, Liaoning 116027, P.R. China

E-mail: 1sb0330@163.com

Dr Yan Li, Institute of Cancer Stem Cell, Dalian Medical University, 9 West Section Lushun South Road, Dalian, Liaoning 116044, P.R. China

E-mail: 1y316@126.com

${ }^{*}$ Contributed equally

Key words: metformin, intrahepatic cholangiocarcinoma cells, proliferation, chemosensitivity to recent epidemic studies (1-3). As compared to insulin or sulfonylureas administration, metformin use may markedly reduce the cancer risk in patients with type II diabetes. Recent studies have confirmed the anti-proliferation effect on various human cancer cell types, such as pancreas (4), prostate (5), breast (6), stomach (7) and liver (8). Metformin inhibits the pro-proliferation effect of insulin receptor- and IGF receptor-dependent signaling by reducing insulin resistance. Furthermore, metformin activates AMP-activated protein kinase (AMPK) and subsequently inhibits activation of mammalian target of rapamycin (mTOR) to prevent proliferation of tumor cells, and activates p53 protein-inducing cell cycle arrest of tumor cells. Several studies have indicated that metformin can potentiate the effect of chemotherapeutic agents or reverse drug resistance in cancer cells (8-10). However, the mechanism of the anti-cancer effects of metformin remains unclear.

A recent epidemiological study that included 1,828 potential intrahepatic cholangiocarcinoma (ICC) patients described that metformin use was significantly associated with a $60 \%$ reduction in ICC risk in diabetic patients (11). Cholangiocarcinoma (CC)categorized as intrahepatic and extrahepatic cholangiocarcinoma (ECC) is highly lethal. ICC is the second most common type of primary liver cancer and its incidence and mortality rates have been rising in recent decades (12-15). Less than $30 \%$ of patients with ICC have the opportunity to have radical operation at diagnostic presentation. Apart from radical operation, some treatment approaches such as systemic chemotherapy, transarterial chemoembolization and radiofrequency ablation may be applied at advanced stages of ICC; however, none of the approaches can significantly improve the prognosis of ICC. Thus, new treatment strategies are needed for ICC.

In the present study, we showed that metformin inhibited the growth of ICC cells by inducing apoptosis and cell cycle arrest and inhibiting colony formation. Metformin inhibited growth by activation of the AMPK/mTOR complex 1 (mTORC1) pathway. Furthermore, metformin amplified the effect of chemotherapeutic agents such as gemcitabine, 5-fluorouracil, arsenic trioxide $\left(\mathrm{As}_{2} \mathrm{O}_{3}\right)$ and sorafenib. Metformin might 
target the mTOR/hypoxia inducible factor $1 \alpha(\mathrm{HIF} 1 \alpha) /$ multidrug resistance proteins 1 (MRP1) signaling pathway and extracellular signal regulated kinases $1 / 2$ (ERK) to sensitize the ICC cells to chemotherapy.

\section{Materials and methods}

Cell cultures. The ICC cell lines RBE and HCCC-9810 were purchased from the Type Culture Collection of the Chinese Academy of Sciences (Shanghai, China). The cell lines were cultured in RPMI-1640 (Gibco, USA) supplemented with 10\% fetal bovine serum (FBS; Gibco) and $100 \mu \mathrm{g} / \mathrm{ml}$ each of penicillin and streptomycin (Invitrogen, USA) in $5 \% \mathrm{CO}_{2}$ at $37^{\circ} \mathrm{C}$.

Reagents. Metformin (1,1-dimethylbiguanide hydrochloride, \#D150959-5G), gemcitabine (2'-Deoxy-2',2'-difluorocytidine, \#G6423-10MG) and 5-fluorouracil (2,4-dihydroxy-5-fluoropyrimidine, \#F6627-1G) were purchased from Sigma-Aldrich (St. Louis, MO, USA). Sorafenib $\left(\mathrm{C}_{21} \mathrm{H}_{16} \mathrm{ClF}_{3} \mathrm{~N}_{4} \mathrm{O}_{3} \mathrm{C}_{7} \mathrm{H}_{8} \mathrm{O}_{3} \mathrm{~S}\right.$, CAS 475207-59-1) was purchased from Selleck Chemicals (Houston, TX, USA). The Cell Counting Kit-8 (CCK-8, KGA317), the Annexin V-FITC Apoptosis Detection Kit (KGA108) and the Cell Cycle Detection Kit (KGA512) were purchased from KeyGen Biotech (Nanjing, China).

Antibodies. The following antibodies were used in western blot analysis: $\beta$-actin (sc-47778, diluted 1:1,000) was from Santa Cruz Biotechnology, Inc., (Santa Cruz, CA, USA). HIF-1 $\alpha$ (N-term) (AP4776a, diluted 1:1,000), active Caspase-3 (AJ1131b, diluted 1:1,000), Bcl-2 (AJ1082a, diluted 1:1,000), CDK4 (AP7520b, diluted 1:1,000) and Cyclin D1 (AP2612c, diluted 1:1,000) were from Abgent (San Diego, CA, USA). AMPKa (Ab-172, \#B0003, diluted 1:500) and phosphorylated AMPK $\alpha$ (Phospho-Thr ${ }^{172}$, \#A0003, diluted 1:500), mTOR (\#B7156, diluted 1:500) and phosphorylated mTOR (Phospho-Ser ${ }^{248}$, \#A7156, diluted 1:500) were from Assay Biotech (Sunnyvale, CA, USA). MRP1 (PA5-30594, diluted 1:500) was from Thermo Fisher Scientific Inc., (Rockford, IL, USA). Phosphorylated Raptor (Phospho-Ser ${ }^{792}$, \#2083, diluted 1:1,000), phosphorylated p70 S6Kinase(Phospho-Thr ${ }^{389}$,\#9234, diluted 1:1,000), phosphorylated 4E-BP1 (Phospho-Thr ${ }^{37 / 46}$, \#2855, diluted 1:1,000), ERK (\#4696, diluted 1:2,000) and phosphorylated ERK (Phospho-Thr ${ }^{202} / \mathrm{Tyr}^{204}, \# 4370$, diluted 1:2,000) were from Cell Signaling Technology, Inc. (Danvers, MA, USA). Goat anti-rabbit and goat anti-mouse IgG, peroxidase-conjugated secondary antibodies (31460 and 31430, both diluted 1:10,000) were from Thermo-Pierce (Rockford, IL, USA).

Cell viability assay. Cell viability was determined using the CCK-8 assay according to the manufacturer's instructions. Cells $\left(5 \times 10^{3}\right)$ were seeded into a well of a 96-well plate and cultured in $100 \mu \mathrm{l}$ of RPMI-1640 supplemented with $10 \%$ FBS, $100 \mu \mathrm{g} / \mathrm{ml}$ penicillin and $100 \mu \mathrm{g} / \mathrm{ml}$ streptomycin. After $24 \mathrm{~h}$, metformin $(0,1,5,10,20,40 \mathrm{mmol} / \mathrm{l})$ was added into the culture medium. Then, after the cells were incubated at $37^{\circ} \mathrm{C}$ for different times $(24,48,72 \mathrm{~h})$, the medium was exchanged for $100 \mu \mathrm{l}$ of RPMI-1640 and $10 \mu \mathrm{l}$ of CCK-8 reagent. The cells were incubated for $2 \mathrm{~h}$ at $37^{\circ} \mathrm{C}$. Finally, the optical density was measured using an EnSpire ${ }^{\mathrm{TM}} 2300$ Multilabel Reader
(PerkinElmer, Waltham, MA, USA) at $450 \mathrm{~nm}$. Five replicates were prepared for each condition. The mean values were calculated and growth cures were drawn.

Clonogenic assay. The inhibitory effect of metformin on ICC cell proliferation was also determined by clonogenic assay. Logarithmic-phase ICC cells were trypsinized and collected, and then resuspended cells were seeded into 6-well plates in triplicates at a density of 500 cells/well in $2 \mathrm{ml}$ of medium containing $10 \%$ FBS. After $48 \mathrm{~h}$ incubation, cultures were replaced with fresh medium contain 0,1 , and $2.5 \mathrm{mM}$ metformin and 2\% FBS, and grown for 2 weeks. The cell clones were stained by a solution containing $1 \%$ crystal violet and $25 \%$ methanol for $2 \mathrm{~min}$. The excess dye was removed by gently rinsing with tap water for $15 \mathrm{~min}$. The clones were visually counted and the percentage of cells that initiated a clone was determined as clonogenicity (number of clones/500x100\%).

Western blot analysis. Cells after different treatments were harvested and lysed in RIPA buffer (KGP702), supplemented with $1 \mathrm{mM}$ phenylmethylsulfonyl fluoride (PMSF; KGP610) and $1 \mathrm{mM}$ phosphatase inhibitor cocktails (KGP602; all from KeyGen Biotech). The mixture was centrifuged at $12,000 \mathrm{x} \mathrm{g}$ for $20 \mathrm{~min}$, and the supernatant was collected. The protein concentration was determined using the BCA assay kit (KGPBCA), and each sample contained $30 \mu \mathrm{g}$ protein per $10 \mu \mathrm{l}$. The protein samples were mixed with loading buffer (KGP101) and the proteins were separated using 6 or $10 \%$ sodium dodecyl sulfate-polyacrylamide gel electrophoresis (SDS-PAGE) and transferred to polyvinylidene difluoride (PVDF) membranes (Bio-Rad Laboratories, Hercules, CA, USA). After soaking in blocking buffer for $2 \mathrm{~h}$, the blots were incubated at $4^{\circ} \mathrm{C}$ overnight with the primary antibody and were subsequently incubated at $37^{\circ} \mathrm{C}$ for $1 \mathrm{~h}$ with the HRP-conjugated secondary antibody. The bands were visualized by chemiluminescence, they were imaged using a ChemiDoc XRS and were analyzed using Image Lab (both from Bio-Rad).

Flow cytometric analysis. To evaluate the effects on cell cycle arrest and induction of apoptosis by metformin, the cells were examined using the Annexin V-FITC Apoptosis Detection Kit and the Cell Cycle Detection Kit according to the manufacturer's protocols. RBE and HCCC-9810 cells were seeded into 6 -well plates $\left(1 \times 10^{5}\right.$ and $2 \times 10^{5}$ cells/dish for analysis of cell cycle arrest and apoptosis, respectively). For cell cycle analysis, after treatment with metformin $(0,1,5$, $10,20,40 \mathrm{mmol} / \mathrm{l})$ for $48 \mathrm{~h}$, a total of $1 \times 10^{6}$ cells was pelleted by centrifugation and washed twice with PBS. Then, the cell pellets were resuspended in $500 \mu 1$ of ice-cold $70 \%$ ethanol and incubated at $4^{\circ} \mathrm{C}$ overnight. The fixed cells were centrifuged and the pellets were washed with PBS. After incubation with $100 \mu \mathrm{l} \mathrm{RNase} \mathrm{A}(10 \mu \mathrm{g} / \mathrm{ml})$ for $30 \mathrm{~min}$ at $37^{\circ} \mathrm{C}$ in the dark, the cells were resuspended in $400 \mu \mathrm{l} \mathrm{PI}(50 \mu \mathrm{g} / \mathrm{ml})$ and placed at $4^{\circ} \mathrm{C}$ in the dark for $30 \mathrm{~min}$. The stained cells were analyzed using an Accuri C6 flow cytometer (Accuri Cytometers Inc., Ann Arbor, MI, USA). For the apoptosis analysis, the cells were trypsinized, washed with cold PBS and suspended in PBS. Then, the cells were stained using the Annexin V-FITC 
A

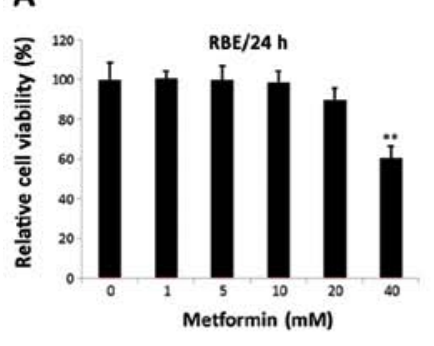

E

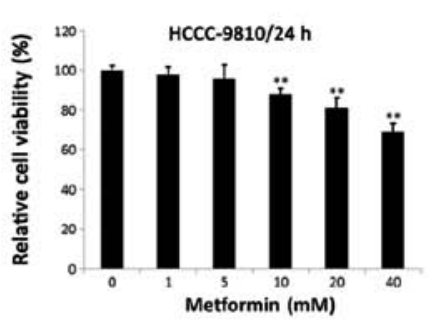

I
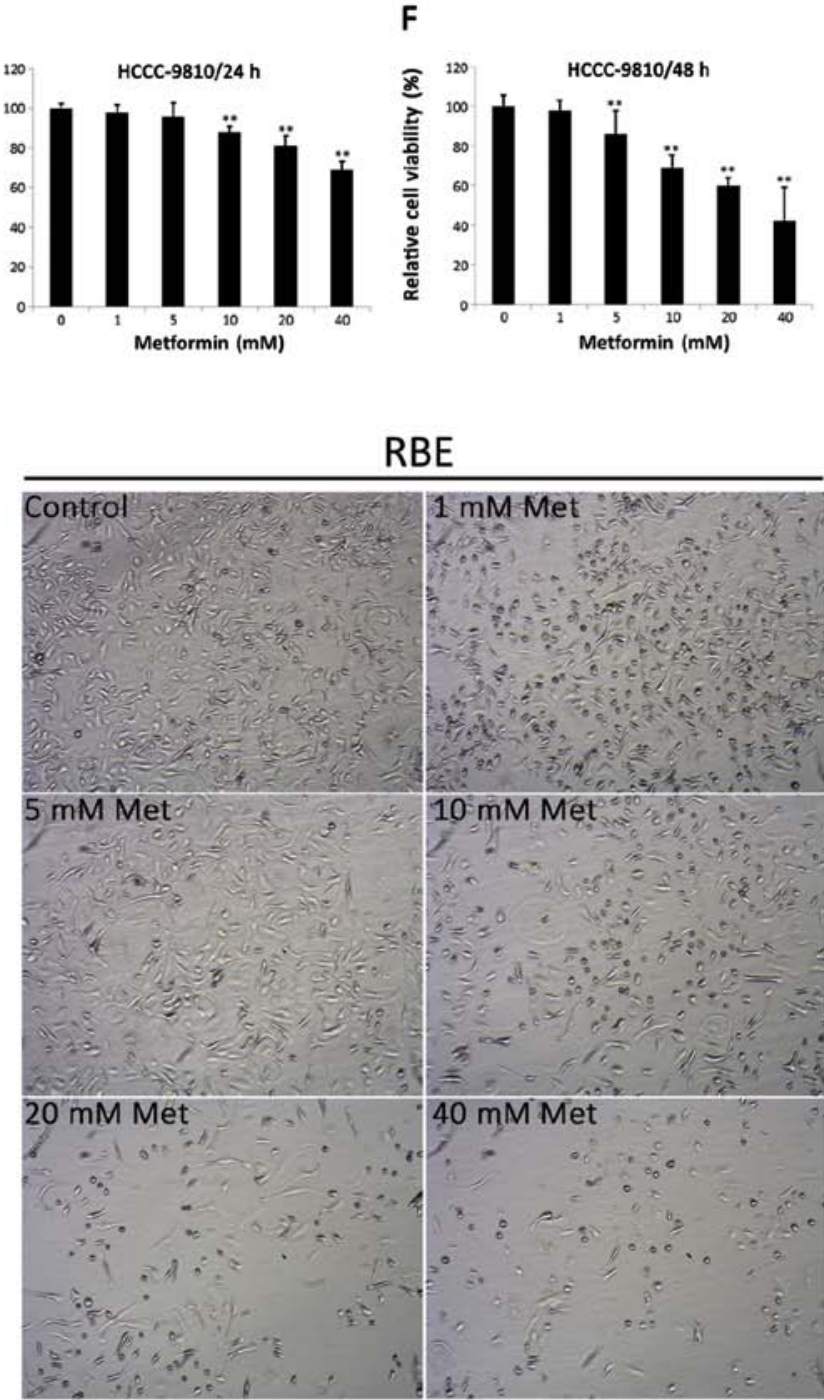

C

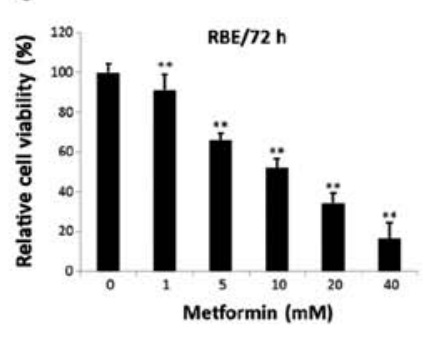

G

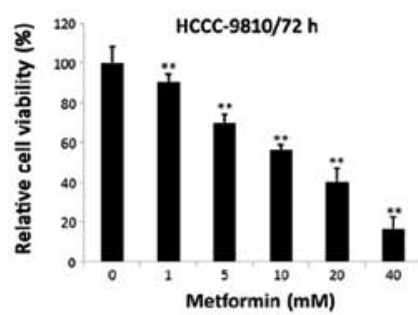

Metformin (mM)

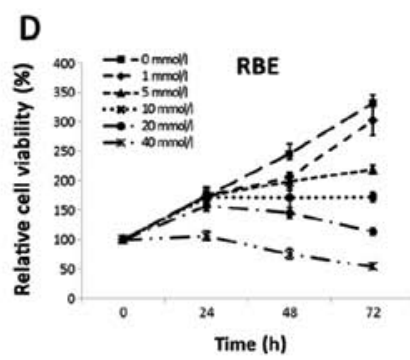

H

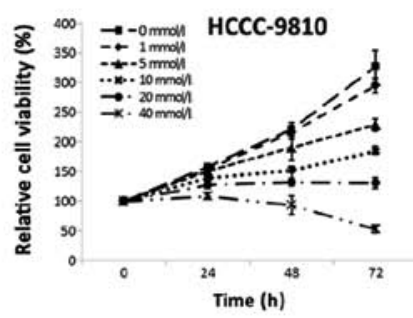

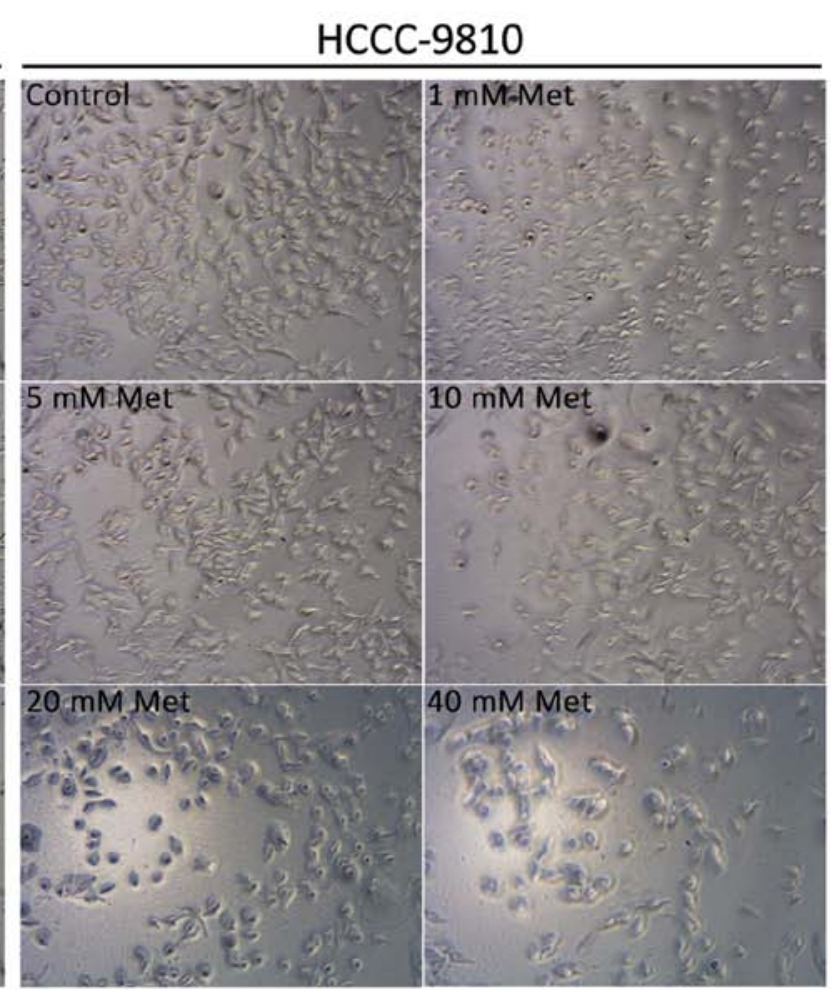

Figure 1. Metformin inhibits proliferation of ICC cells. (A-H) RBE and HCCC-9810 cells were treated with increasing doses of metformin (0-40 mM) for 24, 48, $72 \mathrm{~h}$ incubation. Then, the CCK-8 assay was used to determine cell viability. The experiments were repeated 3 times independently and the bars represent the means $\pm \mathrm{SD}\left({ }^{* *} \mathrm{P}<0.01\right)$. (I) Morphology of RBE and HCCC-9810 cells after treatment with metformin for $48 \mathrm{~h}$ (x10 magnification).

reaction reagent $(5 \mu \mathrm{l}$ of Annexin V-FITC, $5 \mu \mathrm{l}$ of propidium iodide) at $37^{\circ} \mathrm{C}$ for $30 \mathrm{~min}$ in the dark. The stained cells were analyzed using an Accuri C6 flow cytometer (Accuri Cytometers Inc).

Statistical analysis. SPSS 13.0 statistical software was used for the statistical analysis. Values are presented as the mean \pm SD. Statistical analyses were performed using Student's t-test. The analysis of multiple groups was performed with ANOVA with an appropriate post hoc test.

\section{Results}

Metformin inhibits the proliferation of ICC cells. The effects of metformin on the proliferation of ICC cells were investigated in RBE and HCCC-9810 cell lines using CCK-8 assay. As shown in Fig. 1A-H, metformin significantly reduced cell viability in a dose- $(0-40 \mathrm{mM})$ and time-dependent $(24$, 48, $72 \mathrm{~h}$ ) manner in both RBE and HCCC-9810 cell lines. With the $5 \mathrm{mM}$ metformin and 48-h incubation, the two cell lines showed statistical differences in relative cell viability 
A

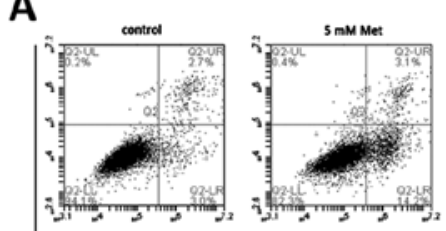

PI

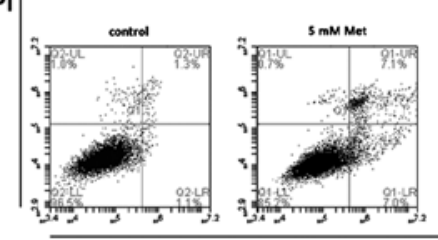

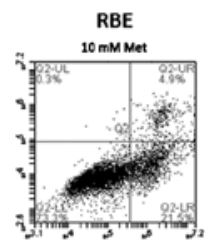

HCCC-9810

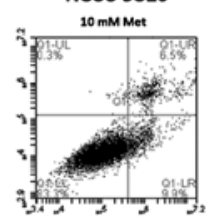

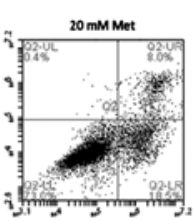
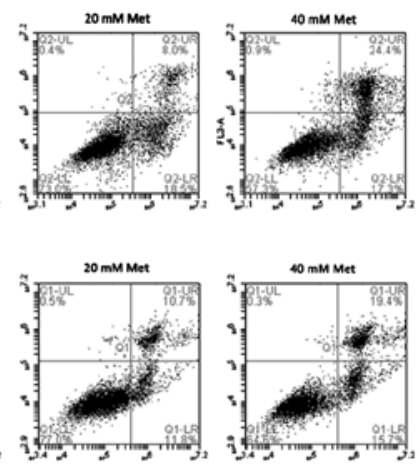

B
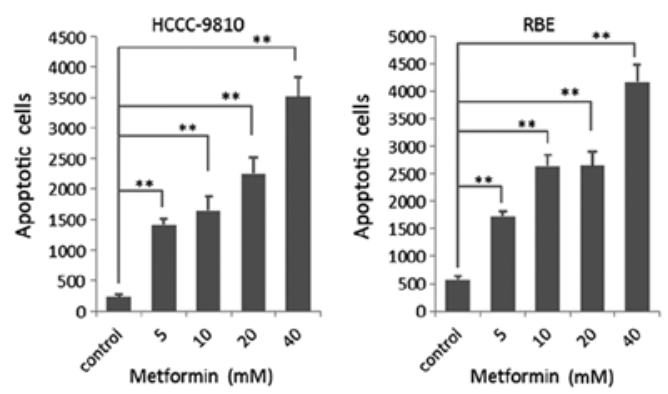

Annexin V-FITC

C

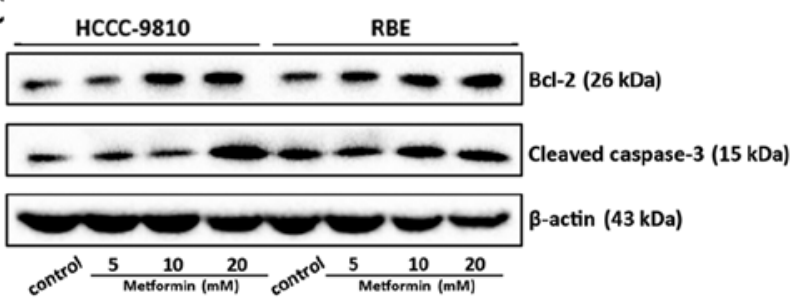

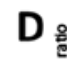

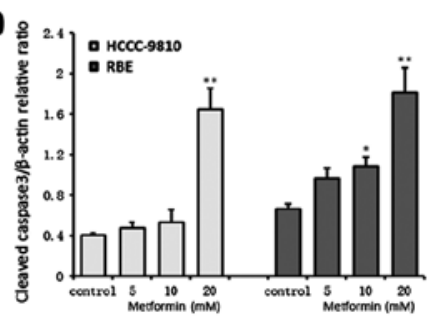

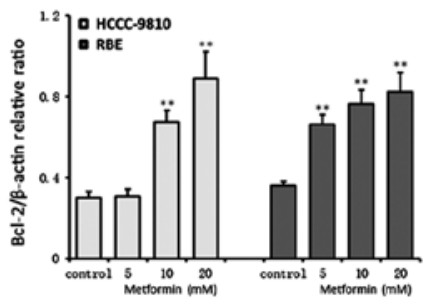

Figure 2. Metformin facilitates apoptosis in ICC cells. (A) After treatment with increasing doses of metformin $(0-40 \mathrm{mM})$ for $48 \mathrm{~h}$ incubation, RBE and HCCC-9810 cells were examined using Annexin V/PI staining. Then, the distribution of apoptotic cells was measured by flow cytometric analysis. (B) The percentages of early apoptosis plus late apoptosis/necrosis are shown in the bar graph $\left({ }^{* *} \mathrm{P}<0.01\right)$. (C) Cleaved caspase-3 and Bcl-2 were monitored using western blot analysis, and (D) band intensities were shown after semi-quantification using Image Lab 5.0 software and normalized with $\beta$-actin and are represented as the means \pm SD from 3 independent experiments $\left({ }^{*} \mathrm{P}<0.05,{ }^{* *} \mathrm{P}<0.01\right)$.

A

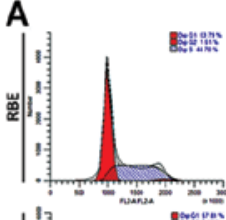

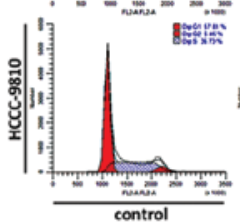

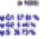
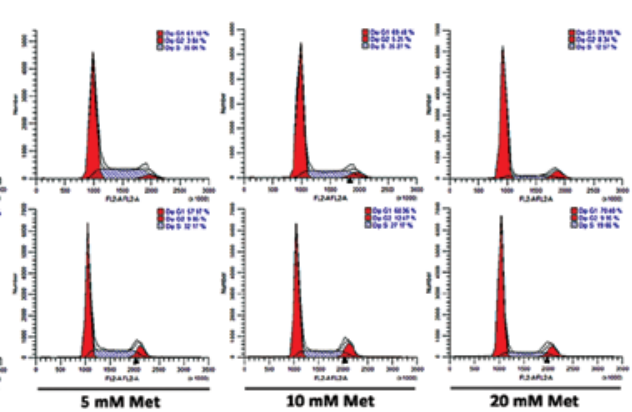

C

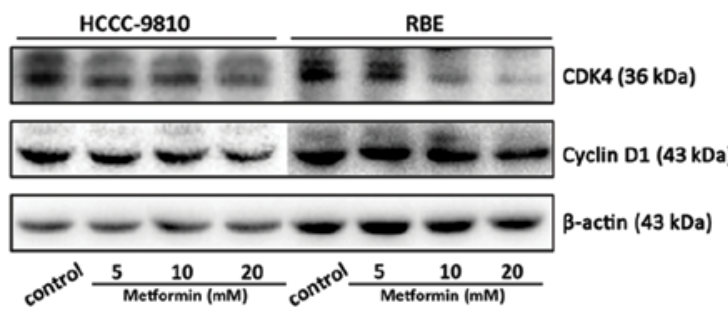

B
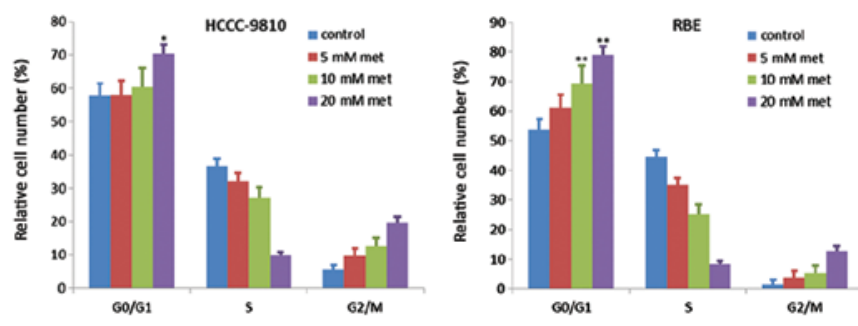

D

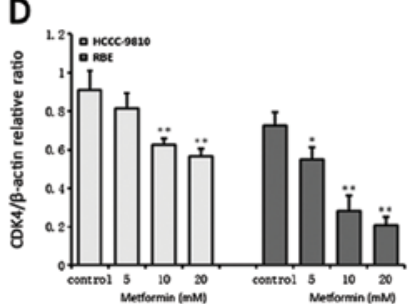

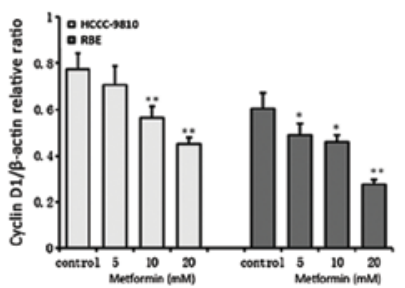

Figure 3. Treatment with metformin induces G0/G1 cell cycle arrest in ICC cells. (A) After treatment with increasing doses of metformin (0-20 mM) for $48 \mathrm{~h}$ incubation, RBE and HCCC-9810 cells were examined using PI staining. Then, the cell cycle distribution was measured by flow cytometric analysis. (B) The percentages of cell cycle distribution are shown in the bar graph $\left({ }^{*} \mathrm{P}<0.05,{ }^{* *} \mathrm{P}<0.01\right)$. (C) Cyclin D1 and CDK4 were monitored using western blot analysis, and (D) band intensities were shown after semi-quantification using Image Lab 5.0 software and normalized with $\beta$-actin and are represented as the means \pm SD from 3 independent experiments $\left({ }^{*} \mathrm{P}<0.05,{ }^{* *} \mathrm{P}<0.01\right)$.

compared to the control cells. The microscopic examination showed a significant decrease of cell density and change of cell morphology, which displayed a smaller and granulated shape in metformin treated cells (Fig. 1I). Taken together, the results show that metformin inhibits the proliferation of ICC cells.
Metformin promotes apoptosis and induces G0/G1 cell cycle arrest in ICC cells. The number of apoptotic cells and percentages of cell cycle distribution were examined after $48 \mathrm{~h}$ metformin incubation by flow cytometric analysis. A significant increase in the number of apoptotic cells and cells 

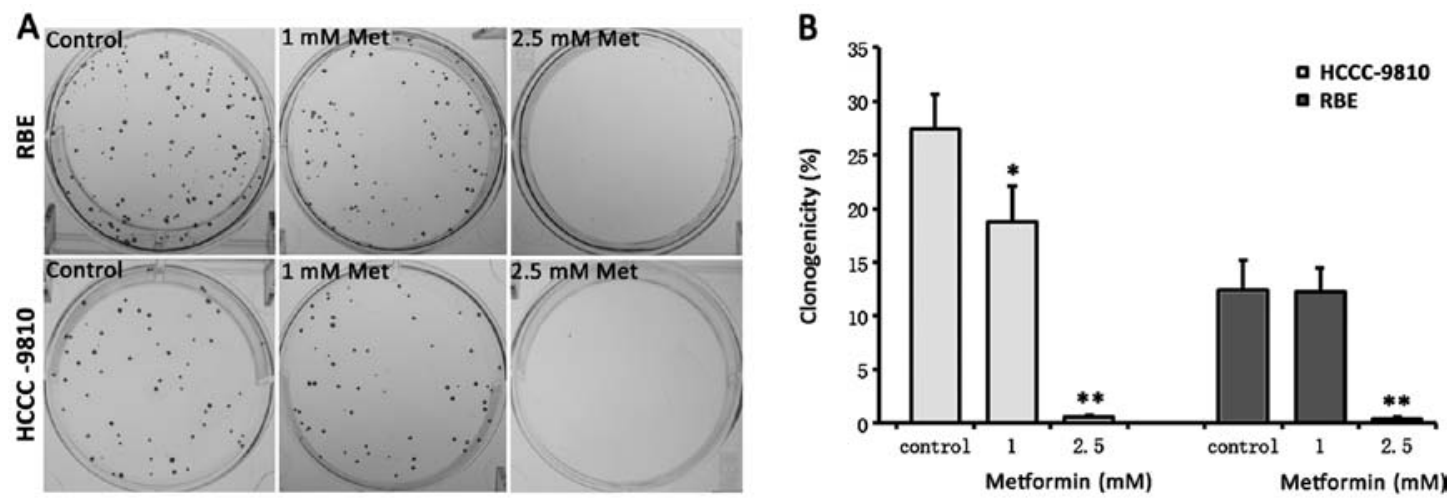

Figure 4. Metformin inhibits colony formation of ICC cells. (A) RBE and HCCC-9810 cells were grown in 6-well plates (500 cells/well) in triplicates. After $48 \mathrm{~h}$, cultures were replaced with fresh medium contain 0,1 , and $2.5 \mathrm{mM}$ metformin and $2 \%$ FBS. After 2 weeks, the colonies were stained with $1 \%$ crystal violet and counted. (B) Bars represent the means $\pm \mathrm{SD}$ from 3 independent experiments ( $\mathrm{P}<0.05,{ }^{* *} \mathrm{P}<0.01$ ).
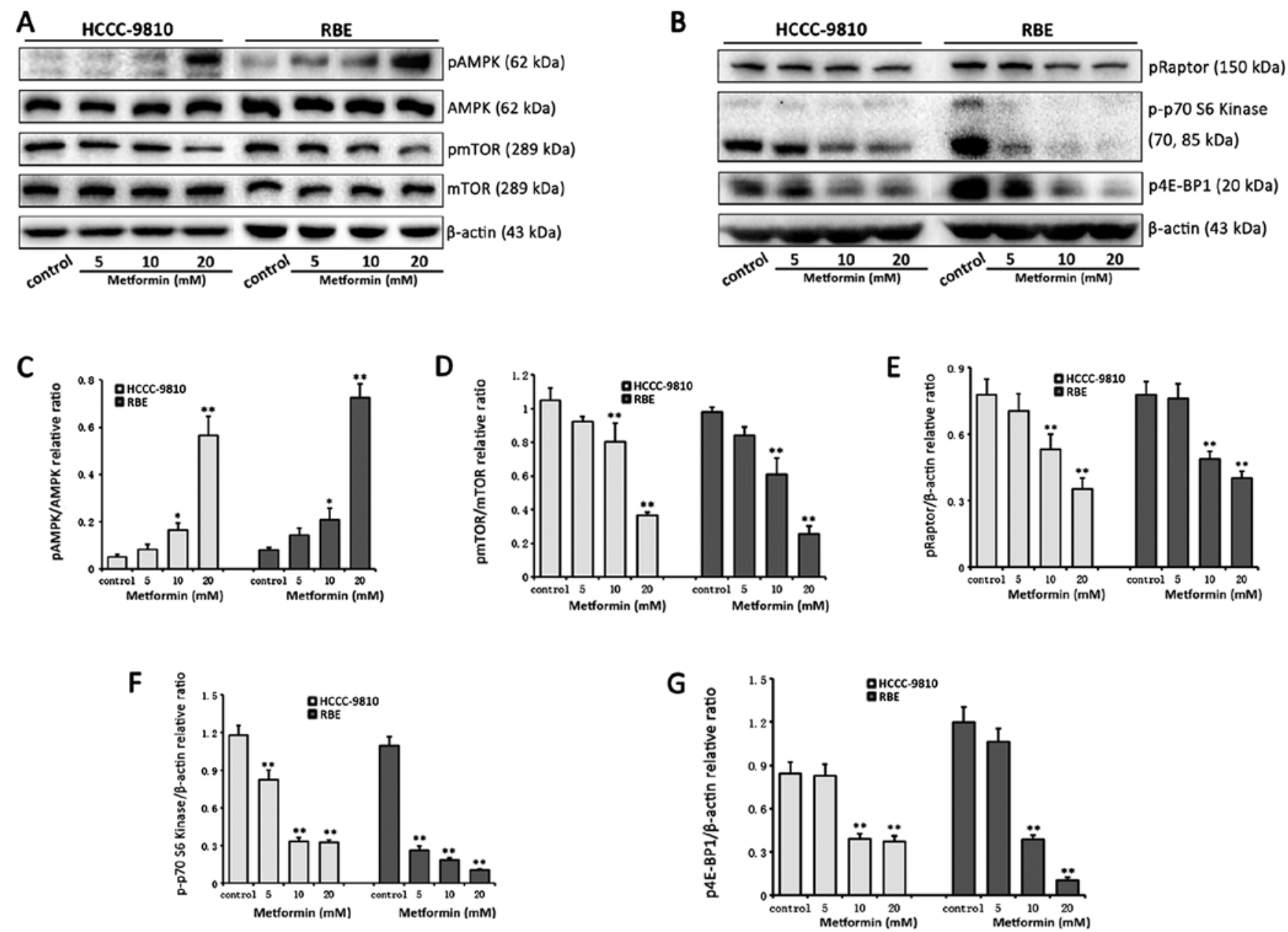

Figure 5. Metformin treatment increases AMPK phosphorylation and inhibits the activation of mTORC1 complex. (A) The phosphorylation of AMPK was upregulated and the phosphorylation of mTOR was downregulated depending on the dose of metformin $(0-20 \mathrm{mM})$. (B) The phosphorylation of Raptor, p70 S6 kinase and 4E-BP1 was downregulated depending on the dose of metformin $(0-20 \mathrm{mM})$. (C-G) The band intensities were quantified using Image Lab 5.0 software and are represented as the means $\pm \mathrm{SD}$ from 3 independent experiments $\left({ }^{*} \mathrm{P}<0.05,{ }^{* * *} \mathrm{P}<0.01\right)$.

undergoing G0/G1 cell cycle arrest was observed in RBE and HCCC-9810 cells with metformin treatment compared with the control cells (Figs. 2A and B; 3A and B). With $48 \mathrm{~h}$ metformin treatment, the percentages of early apoptotic and late apoptotic/necrotic were increased from $5.7 \pm 0.7 \%$ to $41.7 \pm 3.1 \%$ in $\mathrm{RBE}$ cells and $2.4 \pm 0.4 \%$ to $35.1 \pm 3.21 \%$ in HCCC-9810 cells, and the G0/G1 phase cells were increased from $53.79 \pm 3.59 \%$ to $79.09 \pm 2.79 \%$ in RBE cells and $57.81 \pm 3.56 \%$ to $70.40 \pm 2.81 \%$ in HCCC-9810 cells, depending on the metformin doses. 
A

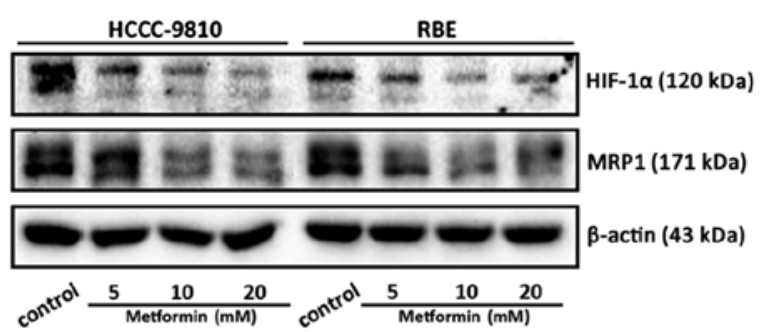

B

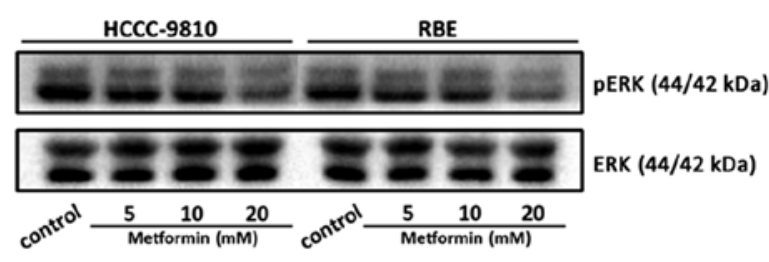

C

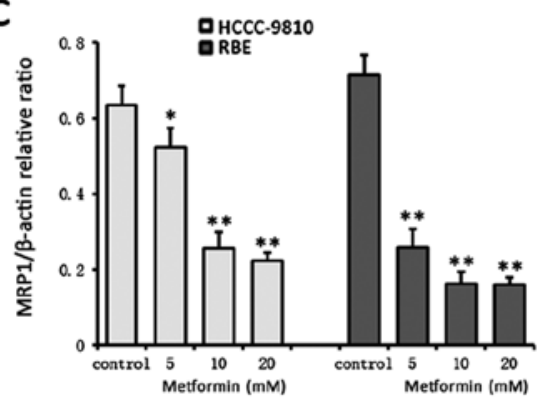

D

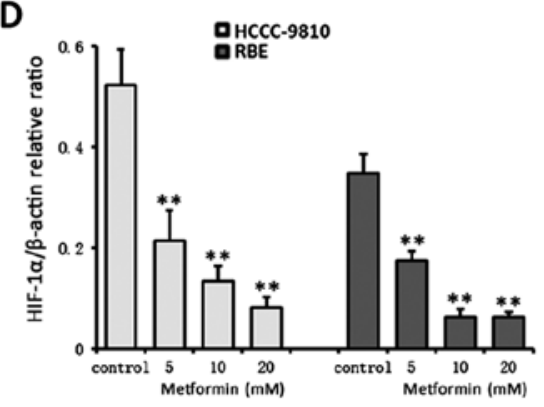

E

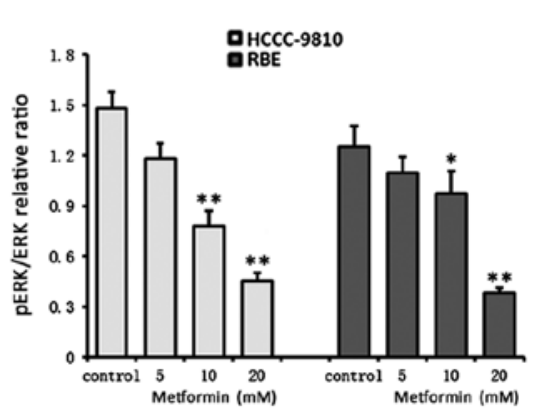

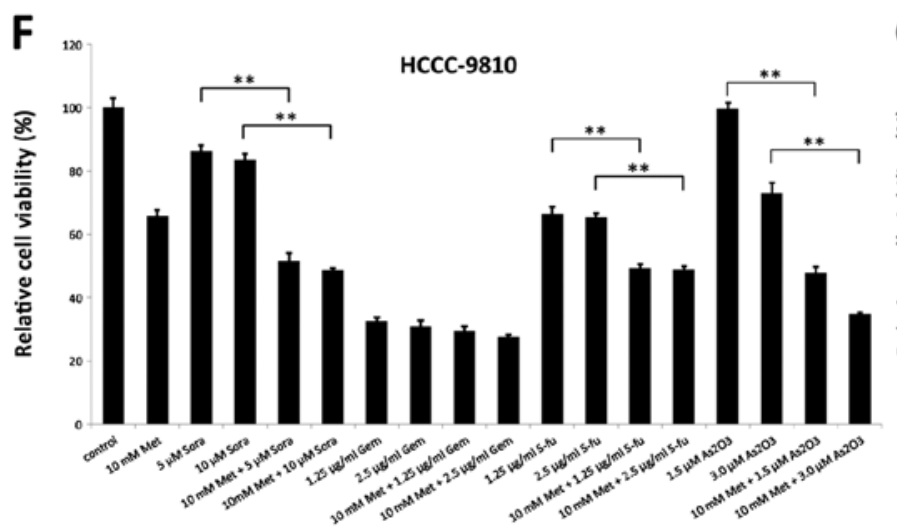

$\mathbf{G}$

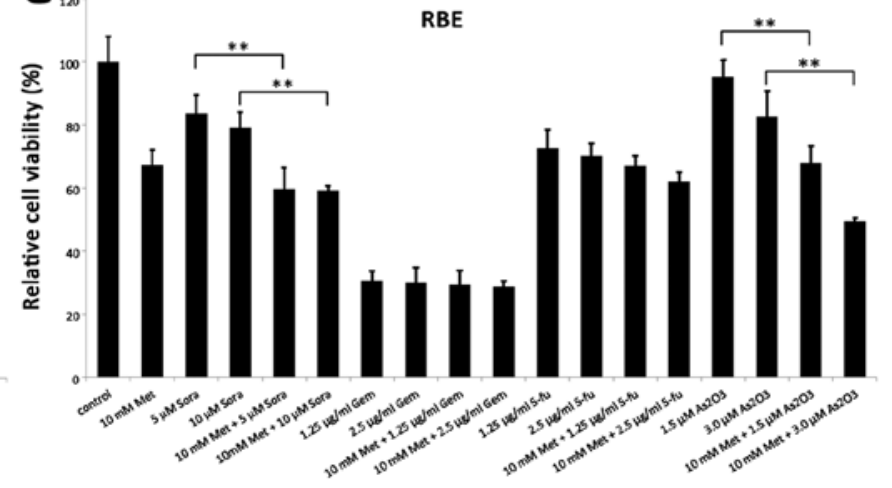

Figure 6. Metformin sensitizes ICC cells to certain chemotherapeutic agents and the potential mechanisms. RBE and HCCC-9810 cells were treated with a combination of metformin and one of the chemotherapeutic agents, sorafenib (sora), gemcitabine (gem), 5-fluorouracil (5-fu) and arsenic trioxide ( $\mathrm{As}_{2} \mathrm{O}_{3}$ ). (A) The expression of HIF-1 $\alpha$ protein and MRP1 protein was downregulated depending on the dose of metformin determined using western blotting. (B) The phosphorylation of ERK was downregulated depending on the dose of metformin. (C-E) All the band intensities were shown after semi-quantification using Image Lab 5.0 software and normalized with $\beta$-actin or total EKR and are represented as the means \pm SD from 3 independent experiments $\left({ }^{*} \mathrm{P}<0.05,{ }^{* *} \mathrm{P}<0.01\right)$. (F and G) RBE and HCCC-9810 cells were treated with sora (5 or $10 \mu \mathrm{M})$, gem $(1.25$ or $2.5 \mu \mathrm{g} / \mathrm{ml}), 5$-fu $(1.25$ or $2.5 \mu \mathrm{g} / \mathrm{ml})$ and $\mathrm{As}_{2} \mathrm{O}_{3}(1.5$ or $3.0 \mu \mathrm{M})$, respectively, for $48 \mathrm{~h}$. Then, the CCK-8 assay was used to determine cell viability. The cell viability with a combination of agent treatments was compared to the cell viability with a single chemotherapeutic agent treatment, respectively $(" \mathrm{P}<0.01)$.

Furthermore, to confirm the metformin-induced apoptosis and G0/G1 cell cycle arrest in ICC cells, cleaved caspase-3, Bcl-2, cyclin D1 and CDK4 expression were monitored using western blot analysis in RBE and HCCC-9810 cells (Figs. 2C and $\mathrm{D} ; 3 \mathrm{C}$ and $\mathrm{D}$ ). Activation of the apoptosis promoter caspase-3 was related to the metformin-induced apoptosis. However, Bcl-2, known as an apoptosis inhibitor, was upregulated by treatment of metformin in a dose-dependent manner. Cyclin D1 and CDK4, which are responsible for the transition from $\mathrm{G} 0 / \mathrm{G} 1$ to $\mathrm{S}$ phase, were downregulated after metformin treatment. Collectively, these results suggest that metformin promotes apoptosis and induces G0/G1 cell cycle arrest in ICC cells.

Metformin inhibits colony formation of ICC cells. We studied the ability of these two ICC cell lines to form colonies in 6-well plates in the presence or absence of metformin. The RBE cells were more sensitive to $1 \mathrm{mM}$ metformin than HCCC-9810 cells (Fig. 4). At the concentration of $2.5 \mathrm{mM}$ metformin, almost no colonies formed in either cell line.

Metformin targets the AMPK/mTORC1 pathway in ICC cells. To evaluate the specific effect of metformin on the AMPK/mTORC1 pathway, which is widely believed to be the most common target of metformin, western blot analysis was used to evaluate the AMPK/mTORC1 pathway in HCCC-9810 and RBE cells. Metformin treatment resulted in enhanced AMPK phosphorylation and reduced mTOR phosphorylation in a dose-dependent manner in ICC cells. Furthermore, the regulatory protein of mTOR (Raptor), which is identified as an mTOR binding partner, mediates mTOR signaling to downstream targets through binding to mTOR substrates, 
including eIF4E-binding protein 1 (4E-BP1) and p70 S6 kinase. Metformin dose-dependently inhibited the phosphorylation of Raptor, 4E-BP1 and p70 S6 kinase. Taken together, these results suggest metformin targets the AMPK/mTORC1 pathway in ICC cells (Fig. 5).

Metformin targets the HIF-1 1 /MRP1 pathway and ERK and sensitizes ICC cells to certain chemotherapeutic agents. The combination of metformin with one of the following chemotherapeutic agents, sorafenib, gemcitabine, 5-fluorouracil and arsenic trioxide $\left(\mathrm{As}_{2} \mathrm{O}_{3}\right)$ was more effective than certain agents alone (Fig. 6F and G). Markedly, metformin plus sorafenib or $\mathrm{As}_{2} \mathrm{O}_{3}$ significantly enhanced the inhibitory effect on RBE and HCCC-9810 cells induced by a single agent. However, metformin did not significantly sensitize ICC cells to gemcitabine, and alternatively sensitized ICC cells to 5-fluorouracil.

To explore the potential mechanisms related to the chemotherapy sensitization effect of metformin, HIF-1 $\alpha /$ MRP1 and phosphorylation of ERK were analyzed in RBE and HCCC-9810 cells. Western immunoblot analysis revealed that metformin markedly suppressed the expression of HIF-1 $\alpha$ protein and MRP1 protein and decreased the phosphorylation of ERK in a dose-dependent manner (Fig. 6A-E).

\section{Discussion}

ICC is an aggressive malignancy, the incidence and mortality rates of which are increasing worldwide. ICC is difficult to diagnose at an early stage and is associated with a low surgical resection rate. Management of ICC has not achieved significant improvements in recent decades. Metformin is an oral anti-hyperglycemic agent of the biguanide family, which is used first-line for type II diabetes with few side-effects. Recent data also described the anti-proliferation effect of metformin in numerous cancer cells. A recent epidemiological study that included 1,828 potential ICC patients described that metformin use was significantly associated with a $60 \%$ reduction in ICC risk in diabetic patients, demonstrating the potential value of metformin in ICC management. Thus, we investigated the anti-proliferation effect and the mechanisms by which metformin affects the ICC cell lines RBE and HCCC-9810. In addition, we evaluated the pro-sensitive effect of metformin in chemotherapy in ICC cells, the mechanisms of which were also explored.

In the present study, we showed that metformin exhibited a dose- and time-dependent anti-proliferation effect on ICC cell lines RBE and HCCC-9810. Metformin exerted inhibitory effects on the clonogenicity and promoted apoptosis and induced G0/G1 cell cycle arrest in RBE and HCCC-9810 cells, which were consistent with the cell viability variation. The two ICC cell lines showed similar sensitivity to metformin. Notably, expression of Bcl-2, which is known to block apoptosis, was upregulated by treatment of metformin in a dose-dependent manner in our study. To the best of our knowledge, most of the previous studies reported that metformin reduced expression of Bcl-2 $(4,16,17)$. We hypothesize that the ICC cells resist the metformin-induced apoptosis via, paradoxically, upregulation of Bcl-2 protein and, on the other hand, $\mathrm{Bcl}-2$ conversely acts as an apoptosis inhibitor or a promoter by certain mechanisms (18). Our future studies will focus on the exact mechanism by which metformin affects expression of Bcl-2 in ICC cells.

The AMPK/mTORC1 pathway is the most widely believed target of metformin. Metformin inhibited the activation of the mTORC1 by activating AMPK in RBE and HCCC-9810 cells in our study. Although it remains controversial whether activation of mTOR pathway promotes development of cholangiocarcinoma or predicts poor prognosis in patients with cholangiocarcinoma $(19,20)$, our results are in line with numerous other reports describing the inhibitory effect of metformin on cancer cells $(6,10,21)$.

In addition, we detected the inhibitory effect of combination treatment of metformin with sorafenib, gemcitabine, 5-fluorouracil or $\mathrm{As}_{2} \mathrm{O}_{3}$, which have been clinically used for cholangiocarcinoma treatment. Metformin significantly sensitized RBE and HCCC-9810 cells to sorafenib and $\mathrm{As}_{2} \mathrm{O}_{3}$, while metformin alternatively sensitized ICC cells to 5-fluorouracil and did not statistically sensitize ICC cells to gemcitabine. This phenomenon may be explained by the fact that RBE and HCCC-9810 cells were highly sensitive to gemcitabine in our study. In particular, metformin more significantly amplified the inhibitory effect of $\mathrm{As}_{2} \mathrm{O}_{3}$ than other agents in ICC cells, the mechanism of which we will explore in future studies. To approach the potential mechanisms related to the chemotherapy sensitization effect of metformin, we further investigated how metformin suppressed the expression of HIF-1 $\alpha$ and MRP1, which are associated with the multidrug resistance of cancer cells, and decreased the phosphorylation of ERK, which is critical in regulating therapy response of cancer cells (22-24). Recent studies suggested that metformin could improve oxygenation and suppress HIF- $1 \alpha$ accumulation in tumor- or diabetic-related diseases through the activation of the AMPK/ mTOR pathway and the repression of oxygen consumption (25-28). HIF-1, a basic helix-loop-helix transcription factor, plays a significant role in regulating the transcription of various target genes in response to hypoxia (29). HIF-1 $\alpha$ is an oxygenregulated subunit that mediates the essential function of HIF-1. The overexpression of HIF-1 $\alpha$ may contribute to the pathogenesis of tumor resistance to chemotherapy $(30,31)$. MRP1 is regarded as energy-dependent membrane efflux pumps and are widely believed to be transcriptionally regulated by HIF-1 $\alpha$ in multiple human tumors (32-35). Consequently, our results indicated that metformin might target the AMPK/mTOR/ HIF-1 $\alpha /$ MRP1 sensitizing ICC cells to chemotherapeutic agents. Furthermore, decreasing the phosphorylation of ERK, which is also the target of sorafenib and $\mathrm{As}_{2} \mathrm{O}_{3}$ (36-38), might compose the mechanisms by which metformin performed as a chemosensitizer in our study.

In conclusion, our results revealed that metformin inhibits ICC cell proliferation and sensitizes ICC cells to certain chemotherapeutic agents, possibly by mechanisms including apoptosis induction and cell cycle arrest, and targeting the AMPK/mTORC1, AMPK/mTOR/HIF-1 $\alpha /$ MRP1 pathway and ERK. Further studies are required to investigate how metformin increases the expression of Bcl-2 and the impact exerted by Bcl-2 on ICC cells. As it is an inexpensive and widely used antidiabetic drug without severe adverse effects, metformin may be a prospective chemotherapeutic agent or a chemosensitizer in ICC treatment. 


\section{Acknowledgements}

This study was supported by grants from the National Natural Science Foundation of China $(81272368,81102069)$ and the Public Technology Research and Social Development Project of Science and Technology Department of Zhejiang Province (2013C33128).

\section{References}

1. Evans JM, Donnelly LA, Emslie-Smith AM, Alessi DR and Morris AD: Metformin and reduced risk of cancer in diabetic patients. BMJ 330: 1304-1305, 2005.

2. Lee MS, Hsu CC, Wahlqvist ML, Tsai HN, Chang YH and Huang YC: Type 2 diabetes increases and metformin reduces total, colorectal, liver and pancreatic cancer incidences in Taiwanese: a representative population prospective cohort study of 800,000 individuals. BMC Cancer 11: 20,2011.

3. Dowling RJ, Niraula S, Stambolic V and Goodwin PJ: Metformin in cancer: translational challenges. J Mol Endocrinol 48: R31-R43, 2012.

4. Nair V, Pathi S, Jutooru I, et al: Metformin inhibits pancreatic cancer cell and tumor growth and downregulates Sp transcription factors. Carcinogenesis 34: 2870-2879, 2013.

5. Akinyeke T, Matsumura S, Wang X, et al: Metformin targets c-MYC oncogene to prevent prostate cancer. Carcinogenesis 34: 2823-2832, 2013.

6. Alimova IN, Liu B, Fan Z, et al: Metformin inhibits breast cancer cell growth, colony formation and induces cell cycle arrest in vitro. Cell Cycle 8: 909-915, 2009.

7. Kato K, Gong J, Iwama $\mathrm{H}$, et al: The antidiabetic drug metformin inhibits gastric cancer cell proliferation in vitro and in vivo. Mol Cancer Ther 11: 549-560, 2012.

8. Petrushev B, Tomuleasa C, Soritau O, et al: Metformin plus PIAF combination chemotherapy for hepatocellular carcinoma. Exp Oncol 34: 17-24, 2012.

9. Ashinuma H, Takiguchi Y, Kitazono S, et al: Antiproliferative action of metformin in human lung cancer cell lines. Oncol Rep 28: 8-14, 2012

10. Chen G, Xu S, Renko K and Derwahl M: Metformin inhibits growth of thyroid carcinoma cells, suppresses self-renewal of derived cancer stem cells, and potentiates the effect of chemotherapeutic agents. J Clin Endocrinol Metab 97: E510-E520, 2012.

11. Chaiteerakij R, Yang JD, Harmsen WS, et al: Risk factors for intrahepatic cholangiocarcinoma: association between metformin use and reduced cancer risk. Hepatology 57: 648-655, 2013.

12. Patel T: Increasing incidence and mortality of primary intrahepatic cholangiocarcinoma in the United States. Hepatology 33: 1353-1357, 2001.

13. Tyson GL and El-Serag HB: Risk factors for cholangiocarcinoma. Hepatology 54: 173-184, 2011.

14. Khan SA, Thomas HC, Davidson BR and Taylor-Robinson SD: Cholangiocarcinoma. Lancet 366: 1303-1314, 2005.

15. Shaib YH, Davila JA, McGlynn K and El-Serag HB: Rising incidence of intrahepatic cholangiocarcinoma in the United States: a true increase? J Hepatol 40: 472-477, 2004.

16. Chaudhary SC, Kurundkar D, Elmets CA, Kopelovich L and Athar M: Metformin, an antidiabetic agent reduces growth of cutaneous squamous cell carcinoma by targeting mTOR signaling pathway. Photochem Photobiol 88: 1149-1156, 2012.

17. Luo Q, Hu D, Hu S, Yan M, Sun Z and Chen F: In vitro and in vivo anti-tumor effect of metformin as a novel therapeutic agent in human oral squamous cell carcinoma. BMC Cancer 12: $517,2012$.

18. Lin B, Kolluri SK, Lin F, et al: Conversion of Bcl-2 from protector to killer by interaction with nuclear orphan receptor Nur77/TR3. Cell 116: 527-540, 2004.

19. Lee D, Do IG, Choi K, et al: The expression of phospho-AKT1 and phospho-MTOR is associated with a favorable prognosis independent of PTEN expression in intrahepatic cholangiocarcinomas. Mod Pathol 25: 131-139, 2012.
20. Chung JY, Hong SM, Choi BY, Cho H, Yu E and Hewitt SM: The expression of phospho-AKT, phospho-mTOR, and PTEN in extrahepatic cholangiocarcinoma. Clin Cancer Res 15: 660-667, 2009.

21. Liu B, Fan Z, Edgerton SM, et al: Metformin induces unique biological and molecular responses in triple negative breast cancer cells. Cell Cycle 8: 2031-2040, 2009.

22. McCubrey JA, Steelman LS, Chappell WH, et al: Roles of the Raf/MEK/ERK pathway in cell growth, malignant transformation and drug resistance. Biochim Biophys Acta 1773: 1263-1284, 2007.

23. McCubrey JA, Steelman LS, Chappell WH, et al: Ras/Raf/ MEK/ERK and PI3K/PTEN/Akt/mTOR cascade inhibitors: how mutations can result in therapy resistance and how to overcome resistance. Oncotarget 3: 1068-1111, 2012.

24. McCubrey JA, Steelman LS, Chappell WH, et al: Mutations and deregulation of Ras/Raf/MEK/ERK and PI3K/PTEN/Akt/ mTOR cascades which alter therapy response. Oncotarget 3 : 954-987, 2012.

25. Takiyama Y, Harumi T, Watanabe J, et al: Tubular injury in a rat model of type 2 diabetes is prevented by metformin: a possible role of HIF-1alpha expression and oxygen metabolism. Diabetes 60: 981-992, 2011.

26. Ece H, Cigdem E, Yuksel K, Ahmet D, Hakan E and Oktay TM: Use of oral antidiabetic drugs (metformin and pioglitazone) in diabetic patients with breast cancer: how does it affect serum Hif-1 alpha and 8Ohdg levels? Asian Pac J Cancer Prev 13: 5143-5148, 2012.

27. Zannella VE, Pra AD, Muaddi H, et al: Reprogramming metabolism with metformin improves tumor oxygenation and radiotherapy response. Clin Cancer Res 19: 6741-6750, 2013.

28. Sheng B, Liu J and Li GH: Metformin preconditioning protects Daphnia pulex from lethal hypoxic insult involving AMPK, HIF and mTOR signaling. Comp Biochem Physiol B Biochem Mol Biol 163: 51-58, 2012.

29. Li Y and Ye D: Cancer therapy by targeting hypoxia-inducible factor-1. Curr Cancer Drug Targets 10: 782-796, 2010.

30. Rho JK, Choi YJ, Lee JK, et al: Gefitinib circumvents hypoxiainduced drug resistance by the modulation of HIF-1 $\alpha$. Oncol Rep 21: 801-807, 2009.

31. Huang C, Xu D, Xia Q, Wang P, Rong C and Su Y: Reversal of P-glycoprotein-mediated multidrug resistance of human hepatic cancer cells by Astragaloside II. J Pharm Pharmacol 64: 1741-1750, 2012.

32. Zhu H, Luo SF, Wang J, et al: Effect of environmental factors on chemoresistance of HepG2 cells by regulating hypoxia-inducible factor-1alpha. Chin Med J (Engl) 125: 1095-1103, 2012.

33. Ding Z, Yang L, Xie X, et al: Expression and significance of hypoxia-inducible factor-1 alpha and MDR1/P-glycoprotein in human colon carcinoma tissue and cells. J Cancer Res Clin Oncol 136: 1697-1707, 2010.

34. Li DW, Dong P, Wang F, Chen XW, Xu CZ and Zhou L: Hypoxia induced multidrug resistance of laryngeal cancer cells via hypoxia-inducible factor-1alpha. Asian Pac J Cancer Prev 14: 4853-4858, 2013.

35. Chen M, Huang SL, Zhang XQ, et al: Reversal effects of pantoprazole on multidrug resistance in human gastric adenocarcinoma cells by down-regulating the V-ATPases/mTOR/ HIF-1alpha/P-gp and MRP1 signaling pathway in vitro and in vivo. J Cell Biochem 113: 2474-2487, 2012.

36. Woo HY and Heo J: Sorafenib in liver cancer. Expert Opin Pharmacother 13: 1059-1067, 2012.

37. Eguchi R, Fujimori Y, Takeda H, et al: Arsenic trioxide induces apoptosis through JNK and ERK in human mesothelioma cells. J Cell Physiol 226: 762-768, 2011.

38. Petit A, Delaune A, Falluel-Morel A, et al: Importance of ERK activation in $\mathrm{As}_{2} \mathrm{O}_{3}$-induced differentiation and promyelocytic leukemia nuclear bodies formation in neuroblastoma cells. Pharmacol Res 77: 11-21, 2013. 